\title{
ANALISIS PERILAKU KONSUMEN DENGAN MODEL MODIFIED UNIFIED THEORY OF ACCEPTANCE AND USE TECHNOLOGY 2 (UTAUT2) PADA E- COMMERCE TOKOPEDIA
}

\section{Bagus Maulana dan Adi Nurmahdi}

Universitas Mercu Buana, Jakarta, Indonesia

Email: maulanabagus1196@gmail.com, adi.nurmahdi@mercubuana.ac.id

\begin{abstract}
This study aims to find out and analyze the Modified Unified Theory Of Acceptance And Use Technology 2 (UTAUT2) model in Tokopedia. The object of the research is all online shoppers in Gunung Putri who have explored onlineshop accounts and or have purchased products via Tokopedia. The method used in this study was descriptive and verificative method using 100 samples of respondents. The result of data processing is done using PLS-SEM method with the help of smartPLS 3 software. The results showed that performance expectation, effort expectancy, social influence, facilitating condition, and price value, have a positive and significant influence on behavioral intention. The highest statistical $t$ is effort expectancy of 3,429. While other independent variables such as hedonic motivation, habit, and trust proved to have a positive and insignificant effect on behavioral intentions. Meanwhile, facilitating condition, habit, and behavioral intention are shown to directly have a positive and significant effect on use behavior.
\end{abstract}

Keywords: E-Commerce; UTAUT2

\begin{abstract}
Abstrak
Penelitian ini bertujuan mengetahui dan menganalisis model Modified Unified Theory Of Acceptance And Use Technology 2 (UTAUT2) di Tokopedia. Objek pada penelitian yaitu seluruh online shoppers di Gunung Putri yang pernah eksplorasi account onlineshop dan atau pernah membeli produk via Tokopedia. Metode yang digunakan pada penelitian ini adalah metode deskriptif dan verifikatif dengan menggunakan 100 sampel responden. Hasil dari olah data dilakukan dengan menggunakan metode PLS-SEM dengan bantuan software smartPLS 3. Hasil penelitian menunjukkan bahwa performance expectation, effort expectancy, social influence, facilitating condition, dan price value, memiliki pengaruh positif dan signifikan terhadap behavioral intention. Yang mana t statistik tertinggi yaitu effort expectancy sebesar 3,429. Sedangkan variabel independen lainnya seperti hedonic motivation, habit, dan trust terbukti berpengaruh positif dan tidak signifikan terhadap behavioral intention. Sementara itu facilitating condition, habit, dan behavioral intention terbukti secara langsung berpengaruh positif dan signifikan terhadap use behavior.
\end{abstract}

Kata Kunci: E-Commerce, UTAUT2

$\begin{array}{ll}\text { How to cite: } & \text { Maulana, Bagus. dan Adi Nurmahdi., (2021) Eksistensi Keamanan Siber terhadap Tindakan } \\ & \text { Cyberstalking dalam Sistem Pertanggungjawaban Pidana Cybercrime 6(4). http:// 10.36418/syntax- } \\ & \text { literate v6i4.2250 } \\ & 2548-1398 \\ \text { E-ISSN: } & \text { Ridwan Institute }\end{array}$




\section{Pendahuluan}

Pada saat ini perkembangan teknologi dan komunikasi semakin pesat, ditandai dengan kemunculan internet yang sangat memudahkan manusia dalam melakukan berbagai kegiatan. Pengguna internet sudah menjadi kebutuhan sehari-hari bagi masyarakat Indonesia. Berikut data penggunaan internet di Indonesia dari data Asosiasi Penyelenggara Jasa Internet Indonesia (APJII) yang merilis survei penetrasi dan perilaku pengguna. APJII mengungkapkan pengguna paling banyak terhubung setiap harinya dengan internet lewat smartphone $(93,9 \%)$. Pengguna menyebutkan rata-rata waktu yang dibutuhkan dalam sehari untuk menggunakan internet 3-4 jam sehari $(14,1 \%)$. Dari segi konten internet bersifat komersial untuk membeli barang secara online, tertinggi menjawab tidak pernah berkunjung $(53,4 \%)$. Sedangkan mereka yang pernah, mayoritas menjawab shopee (11,2\%), Bukalapak (8,4\%), Lazada $(6,7 \%)$, Tokopedia $(4,3 \%)$, dan Traveloka (2,3\%). Ini artinya ada potensi yang besar untuk $e$ commerce bahwa masih ada banyak pengguna internet yang belum pernah memanfaatkan belanja online.

Pada penelitian ini, penulis mengambil Tokopedia sebagai objek penelitian yang akan digunakan. Data yang dihimpun iprice.co.id menunjukkan Tokopedia menduduki peringkat pertama dengan rerata pengunjung situs web pada Q3 2019 mencapai 65.953.400, dan disusul dengan Shopee mencapai 55.964.700 pengunjung. Dari tahun Q2 2018 Tokopedia sudah merupakan peringkat pertama e-commerce pengunjung terbanyak dari data Iprice.com tetapi di Q4 2019 Tokopedia turun menjadi peringkat kedua, dan Shopee menduduki peringkat pertama.

Dapat diartikan bahwa mengalami penurunan peringkat pengunjung situs web yang tadinya konsisten di peringkat pertama pada Q2 2018. Dalam hal ini, menjadi sebuah fenomena yang menarik dalam kaitannya dengan aktivitas eksplorasi untuk melakukan belanja online. Berdasarkan fenomena tersebut dapat kita duga bahwa Tokopedia perlu memahami perilaku konsumen agar meningkatkan pengguna. Berdasarkan fenomena tersebut dapat kita duga bahwa Tokopedia perlu memahami perilaku konsumen agar meningkatkan pengguna. Perilaku konsumen merupakan studi mengenai bagaimana individu, kelompok, dan organisasi memilih, membeli, memakai dan bagaimana barang, jasa, ide, atau pengalaman untuk memuaskan kebutuhan dan harapan mereka menurut (Kotler \& Keller, 2016). Dari definisi tersebut mengenai perilaku konsumen, bisa ditarik kesimpulan bahwa perilaku konsumen suatu proses keputusan pembelian dan tindakan dalam memperoleh, memakai, dan menghabiskan produk.

Penelitian ini dibuat untuk menganalisis perilaku konsumen dengan menggunakan teori UTAUT2 yang dikembangkan oleh (Venkatesh, Thong, \& Xu, 2012). Pada tahun 2012, Teori UTAUT2 untuk menganalisis bagaimana penerimaan sistem pada penggunaan teknologi dalam sebuah organisasi. 


\section{Metode Penelitian}

Penelitian yang dipakai pada penelitian ini merupakan penelitian deskriptif dan verifikatif. Penelitian deskriptif dalam penelitian ini bertujuan untuk menggambarkan karakteristik variabel. Metode verifikatif dalam penelitian ini dilakukan dengan menguji hipotesis penelitian yang telah dirumuskan. Berdasarkan penelitian deskriptif dan verikatif tersebut, maka dilaksanakan melalui pengumpulan data di lapangan dengan metode explonatory survei dengan membagikan kuesioner kepada responden online shoppers. Berdasarkan dimensi waktu, penelitian ini tergolong ke dalam cross sectional study yaitu pengambilan data hanya dilakukan satu kali saja (Sekaran \& Bougie, 2010).

Teknik sampling yang digunakan adalah purposive sampling dengan menyebarkan kuesioner kepada sampel sebanyak 100 responden online shoppers di Gunung Putri yang pernah eksplorasi account online shop dan atau pernah membeli via Tokopedia. Metode analisis data yang digunakan adalah SEM-PLS menggunakan software SmartPLS 3 untuk mengetahui besaran pengaruh variabel dalam penelitian dengan pengujian model pengukuran (outer model) dan model struktural (inner model).

\section{Hasil dan Pembahasan}

Model Pengukuran (Outer Model) merupakan analisis yang dilakukan untuk memastikan bahwa measurement (model pengukuran) yang digunakan layak untuk dijadikan pengukuran (valid dan reliabel).

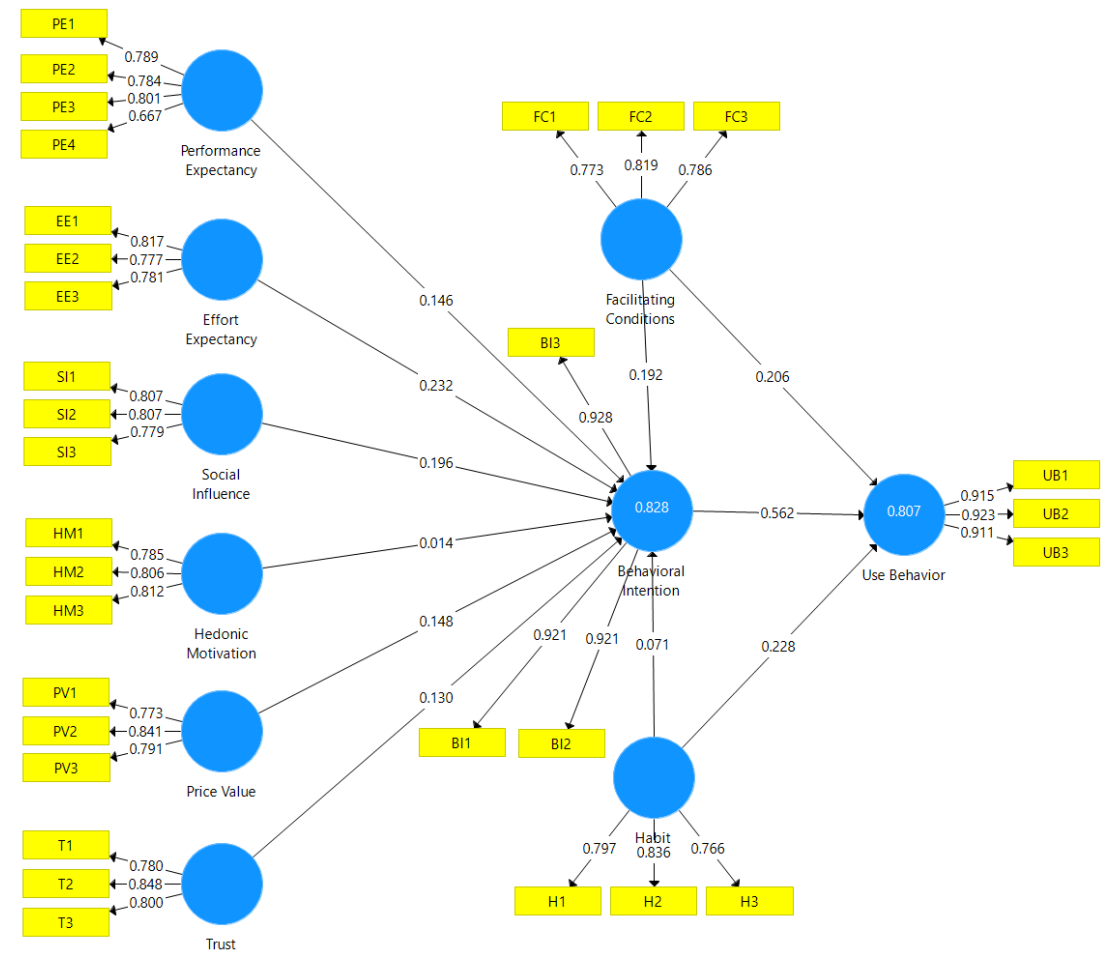

Gambar 1

Hasil Uji Outer Model

Pengukuran model dalam penelitian ini meliputi pengukuran convergent validity, composite reliability dan cronbachalpha, dan average variance extracted 
(AVE). Berdasarkan hasil uji convergent validity, diperoleh bahwa semua dari loading factor $>0,7$ sehingga dapat diartikan semua indikator yang terdapat pada penelitian ini sudah valid dalam mengukur masing-masing variabel latennya. Dan hasil uji semua variabel laten memiliki nilai composite reliability > 0,7 dan cronbach alpha $>0,7$ serta AVE > 0,5 maka dapat disimpulkan variabel laten reliabel dan baik. Hal ini menunjukkan bahwa semua indikator memiliki kekonsistenan dalam mengukur masingmasing konstruknya.

Model Struktural (Inner Model) merupakan model yang menghubungkan variabel laten endogen atau hubungan variabel endogen dengan variabel endogen lainnya. Berdasarkan pengujian bootstraping diperoleh hasil model struktural sebagai berikut :

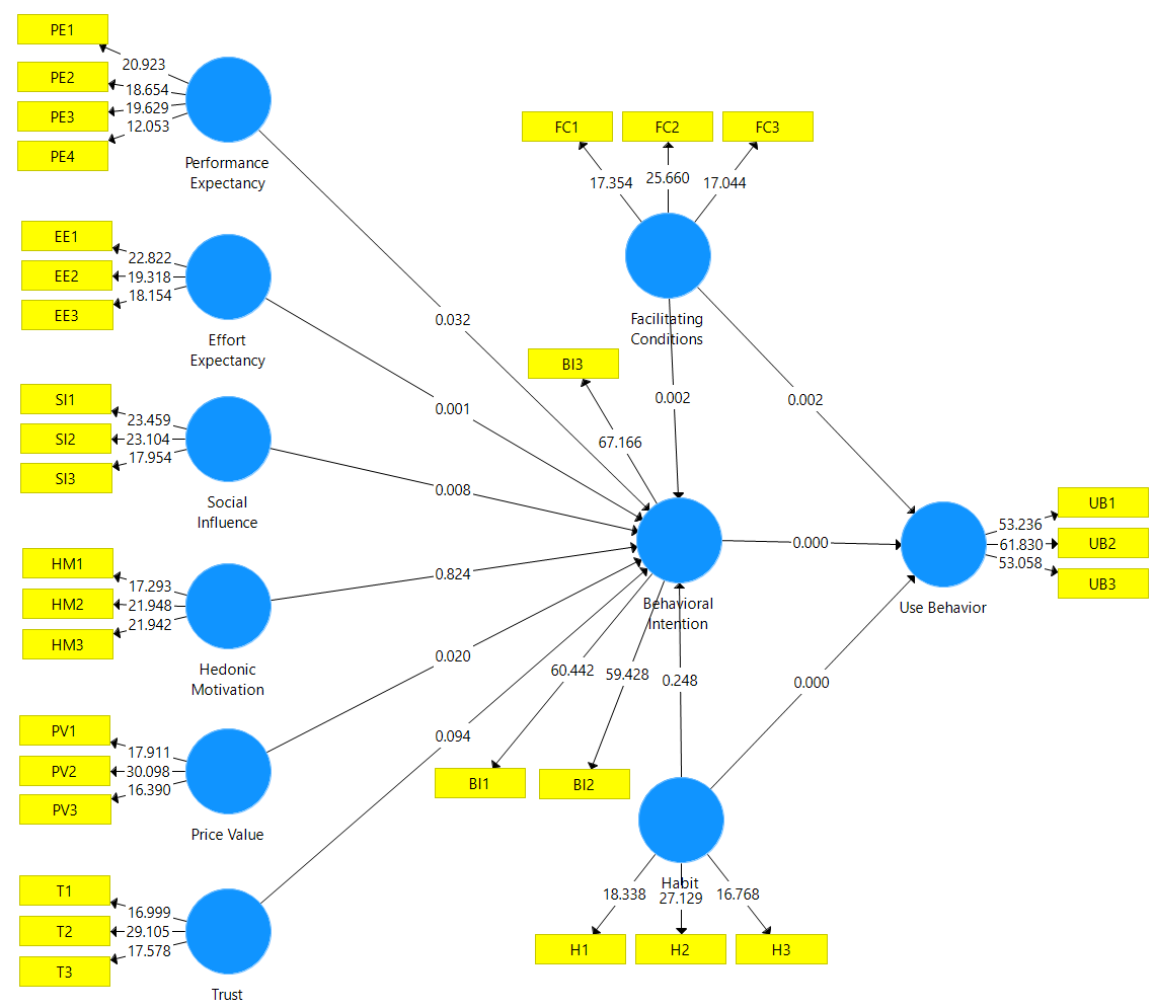

\section{Gambar 2}

\section{Hasil Uji Inner Model (Bootstraping)}

Model struktural dievaluasi dengan menggunakan $\mathrm{R}$ square dan Uji t serta signifikansi koefisien parameter jalur struktural. Hasil uji $\mathrm{R}$ square dapat dilihat pada tabel 1.

\section{Tabel 1}

\section{Hasil Uji R Square}

\begin{tabular}{cc}
\hline Variabel & R Square \\
\hline $\begin{array}{c}\text { Behavioral } \\
\text { Intention }\end{array}$ & 0,828 \\
\hline Use Behavior & 0,807 \\
\hline
\end{tabular}


Diketahui bahwa nilai $\mathrm{R}$ square pada variabel behavioral intention adalah sebesar 0,828 atau 82,8\%. Sehingga variabel performance expectancy, effort expectancy, social influence, facilitating condition, hedonic motivation, price value, habit, dan trust secara simultan mempunyai pengaruh signifikan terhadap behavioral intention sebesar $82,8 \%$. Sedangkan sisanya sebesar 17,2\% dipengaruhi oleh faktor lain di luar model penelitian. Nilai R square pada variabel use behavior adalah sebesar 0,807 atau sebesar $80,7 \%$. Sehingga variabel facilitating condition, habit, dan behavioral intention, secara simultan mempunyai pengaruh signifikan terhadap use behavior sebesar $80,7 \%$. Sedangkan sisanya sebesar 19,3\% dipengaruhi oleh faktor lain di luar model penelitian. Semakin besar angka $\mathrm{R}$ square menunjukkan semakin besar variabel independen tersebut dapat menjelaskan variabel dependen sehingga semakin baik persamaan strukturalnya.

Dalam tahap pengujian hipotesis ini, maka akan di analisis apakah ada pengaruh yang signifikan antara variabel independen terhadap variabel dependen. Untuk mengetahui signifikan atau tidak signifikan dilihat dari $\mathrm{t}$ tabel pada alpha $0.05(5 \%)=$ 1,98. kemudian $\mathrm{t}$ tabel dibandingkan oleh $\mathrm{t}$ hitung ( $\mathrm{t}$ statistik) jika $\mathrm{t}$ hitung $>\mathrm{t}$ tabel maka signifikan dan sebaliknya jika $\mathrm{t}$ hitung $<\mathrm{t}$ tabel maka tidak signifikan atau $\mathrm{P}$ values $>$ 0,05 maka tidak signifikan dan sebaliknya jika $\mathrm{P}$ values $<0,05$ maka signifikan.

Tabel 2

Tabel Path Coefficent

\begin{tabular}{clcccc}
\hline No. & Hipotesis & $\begin{array}{c}\text { Path } \\
\text { Coefficent }\end{array}$ & t Statistik & P Values & Keterangan \\
\hline 1 & $\mathrm{PE} \rightarrow \mathrm{BI}$ & 0,146 & 2,161 & 0,032 & positif - signifikan \\
\hline 2 & $\mathrm{EE} \rightarrow \mathrm{BI}$ & 0,232 & 3,429 & 0,001 & positif - signifikan \\
\hline 3 & $\mathrm{SI} \rightarrow \mathrm{BI}$ & 0,196 & 2,635 & 0,008 & positif - signifikan \\
\hline 4 & $\mathrm{FC} \rightarrow \mathrm{BI}$ & 0,192 & 3,114 & 0,002 & positif - signifikan \\
\hline 5 & $\mathrm{FC} \rightarrow \mathrm{UB}$ & 0,206 & 2,852 & 0,002 & positif - signifikan \\
\hline 6 & $\mathrm{HM} \rightarrow \mathrm{BI}$ & 0,014 & 0,200 & 0,824 & positif - tidak signifikan \\
\hline 7 & $\mathrm{PV} \rightarrow \mathrm{BI}$ & 0,148 & 2,409 & 0,020 & positif - signifikan \\
\hline 8 & $\mathrm{H} \rightarrow \mathrm{BI}$ & 0,071 & 1,132 & 0,248 & positif - tidak signifikan \\
\hline 9 & $\mathrm{H} \rightarrow \mathrm{UB}$ & 0,228 & 4,015 & 0,000 & positif - signifikan \\
\hline 10 & $\mathrm{~T} \rightarrow \mathrm{BI}$ & 0,130 & 1,712 & 0,094 & positif - tidak signifikan \\
\hline 11 & $\mathrm{BI} \rightarrow \mathrm{UB}$ & 0,562 & 8,376 & 0,000 & positif - signifikan \\
\hline
\end{tabular}

Penelitian ini dilakukan untuk mengetahui faktor-faktor pengaruh adopsi $e$ commerce Tokopedia yang ada di daerah Gunung Putri, Bogor. Penelitian ini menggunakan model penerimaan dengan menggunakan UTAUT2 yang diadopsi dari penelitian yang dilakukan oleh (Venkatesh et al., 2012) yang dimodifikasi. Pada penelitian ini terdapat delapan konstruk yaitu performance expectancy, effort expectancy, social influence, facilitating condition, hedonic motivation, price value, habit, dan trust. Serta konstruk yang berpengaruh secara langsung yaitu behavior intention dan use behavior. Berikut pembahasan hasil penelitian pengaruh adopsi $e$ commerce Tokopedia antar variabel pada model modifikasi UTAUT2. 

and Use Technology 2 (UTUT2) pada E-Commerce Tokopedia

Berdasarkan pengujian pengaruh dari variabel performance expectancy terhadap behavior intention terbukti memiliki pengaruh positif dan signifikan. Penelitian terdahulu yang membuktikan hipotesis ini adalah penelitian yang dilakukan oleh (Foon \& Fah, 2011), (Tarhini, El-Masri, Ali, \& Serrano, 2016), (Gupta, Dogra, \& George, 2018), (Venkatesh et al., 2012). Penelitian terdahulu tersebut juga menemukan pengaruh yang signifikan antara performance expectancy dengan behavior intention. Dengan demikian dapat disimpulkan bahwa hipotesis ini diterima dikarenakan tingkat kepercayaan dari responden bahwa dengan belanja online menggunakan Tokopedia memberikan manfaat yang optimal maupun keuntungan bagi masyarakat Gunung Putri.

Berdasarkan pengujian pengaruh dari variabel effort expectancy terhadap behavior intention terbukti memiliki pengaruh positif dan signifikan. Penelitian terdahulu yang membuktikan hipotesis ini adalah penelitian yang dilakukan oleh (Handayani, 2007), (Foon \& Fah, 2011), (Venkatesh et al., 2012), (Indrawati, 2014). Penelitian terdahulu tersebut juga menemukan pengaruh yang signifikan antara effort expectancy dengan behavior intention. Effort expectancy dapat diartikan sebagai tingkat kemudahan yang dirasakan pengguna teknologi seperti sejauh mana teknologi tersebut mempermudah aktivitas pengguna, tidak mempersulit penggunanya untuk bekerja dan sejauh mana teknologi tersebut dapat mempersingkat waktu kerja mereka. Dengan demikian dapat disimpulkan bahwa hipotesis ini diterima dikarenakan masyarakat di Gunung Putri Bogor sudah merasakan dan menemukan tingkat kemudahan ketika belanja online dengan menggunakan Tokopedia.

Berdasarkan pengujian pengaruh dari variabel social influence terhadap behavior intention terbukti memiliki pengaruh positif dan signifikan. Penelitian terdahulu yang membuktikan hipotesis ini adalah penelitian yang dilakukan oleh (Venkatesh et al., 2012), (Tarhini et al., 2016), (Gupta et al., 2018), (Trojanowski \& Kułak, 2017), (Putra \& Ariyanti, 2014). Alasan hipotesis ini menghasilkan nilai yang signifikan yaitu karena masyarakat Gunung Putri yang sebagai responden di penelitian ini memiliki keyakinan bahwa persepsi adopsi penggunaan dari e-commerce Tokopedia tumbuh berdasarkan lingkungan eksternalnya. Jadi persepsi dari orang lain dan sekitarnya mempengaruhi adopsi penggunaan layanan belanja online pada Tokopedia.

Berdasarkan pengujian pengaruh variabel facilitating condition terhadap behavior intention terbukti memiliki pengaruh positif dan signifikan. Penelitian terdahulu yang membuktikan hipotesis ini adalah penelitian yang dilakukan oleh (Putra \& Ariyanti, 2014), (Trojanowski \& Kułak, 2017), (Handayani, 2007), (Tarhini et al., 2016). Penelitian terdahulu tersebut juga menemukan pengaruh yang signifikan antara facilitating condition dengan behavior intention. Hasil ini memungkinkan karena responden memiliki perangkat teknis yang mendukung seperti smartphone, juga memiliki pengetahuan yang cukup untuk menggunakan aplikasi dari Tokopedia.

Serta pengaruh facilitating condition terhadap use behavior didapatkan hasilnya memiliki pengaruh positif dan signifikan. Penelitian sebelumnya yang membuktikan hipotesis dari facilitating condition terhadap behavior intention dan facilitating condition terhadap use behavior adalah penelitian yang dilakukan oleh (Venkatesh et 
al., 2012), (Foon \& Fah, 2011), (Putra \& Ariyanti, 2014), (Trojanowski \& Kułak, 2017). Alasan hipotesis ini diterima karena masyarakat Gunung Putri Bogor adalah karena mereka merasa sumber daya, infrastruktur, teknologi maupun fasilitas pendukung lainnya yang diperlukan dan yang mendukung dalam penggunaan layanan ini tersedia. Sehingga mereka dapat merasakan manfaat dan kegunaan dari layanan e-commerce Tokopedia tersebut.

Berdasarkan pengujian pengaruh variabel hedonic motivation terhadap behavior intention terbukti memiliki pengaruh positif dan tidak signifikan. Penelitian terdahulu yang membuktikan hipotesis ini adalah penelitian yang dilakukan oleh (Harsono \& Suryana, 2014; Indrawati \& Utama, 2018). Namun terdapat pula penelitian terdahulu yang hasilnya berbeda karena hedonic motivation terbukti signifikan mempengaruhi behavioral intention seperti penelitian yang dilakukan oleh (Trojanowski \& Kułak, 2017), (Venkatesh et al., 2012), (Putri, 2018), (Ramdhani, Rachmawati, \& Prabowo, 2017). Dengan demikian dapat disimpulkan bahwa hipotesis ini ditolak dikarenakan belanja online menggunakan Tokopedia belum memberikan tingkat kesenangan tertentu bagi masyarakat Gunung Putri Bogor dari layanan-layanan yang diberikan oleh Tokopedia. Karena responden belum merasa mendapatkan feedback seperti terhibur dengan adanya promosi yang diberikan, kenyamanan menggunakan aplikasi Tokopedia maupun merasa lebih bangga menggunakan Tokopedia dibandingkan e-commerce lain.

Berdasarkan pengujian pengaruh variabel price value terhadap behavior intention terbukti memiliki pengaruh positif dan signifikan. Penelitian terdahulu yang membuktikan hipotesis ini adalah penelitian yang dilakukan oleh (Venkatesh et al., 2012), (Putri, 2018), (Ramdhani et al., 2017), (Putra \& Ariyanti, 2014). Hal ini disimpulkan bahwa pengguna merasa mendapatkan perbandingan lebih antara manfaat yang diterima dari penggunaan e-commerce Tokopedia dengan biaya yang dikeluarkan sebanding, responden juga merasakan bahwa biaya yang dikenakan terkadang lebih murah sehingga dengan adanya biaya lebih murah mempengaruhi pengguna terhadap adopsi teknologi e-commerce Tokopedia ini.

Berdasarkan pengujian pengaruh variabel habit terhadap behavior intention terbukti memiliki pengaruh positif dan tidak signifikan. Hal ini menunjukkan bahwa penggunaan Tokopedia tidak menjadi prioritas utama dalam metode belanja online bagi pengguna, meskipun telah beberapa kali menggunakan layanan tersebut. Hasil penelitian (Limayem, Hirt, \& Cheung, 2007), (Cahyani, 2019), dan (Raman \& Don, 2013) yang juga mengatakan bahwa habit tidak berpengaruh signifikan terhadap behavior intention. Dengan demikian hal ini berarti bahwa belum ada kebiasaan dari adopsi penggunaan e-commerce Tokopedia seperti tidak terbiasa bertransaksi dengan menggunakan metode belanja online ini dalam kehidupan sehari-hari karena lebih terbiasa dengan metode belanja offline yang biasa dilakukan, sehingga hal ini turut serta mempengaruhi responden dalam minat pada adopsi penggunaan e-commerce Tokopedia.

Sementara berdasarkan pengaruh habit terhadap use behavior didapatkan hasilnya memiliki pengaruh positif dan signifikan. Hasil penelitian yang mendukung 
hipotesis penelitian ini adalah penelitian yang dilakukan oleh (Venkatesh et al., 2012) yang mengatakan bahwa habit memiliki kekuatan untuk meningkatkan adopsi dari perilaku pengguna untuk terus menggunakan aplikasi mobile. Penelitian lainnya yaitu menurut (Putri, 2018), (Wibowo \& Ariyanti, 2016) dan (Ramdhani et al., 2017). Hal ini dapat diartikan bahwa kebiasaan dari responden dalam belanja online dengan menggunakan e-commerce Tokopedia mempengaruhi perilaku seseorang dalam menggunakan metode belanja online dari Tokopedia ini.

Berdasarkan pengujian pengaruh variabel trust terhadap behavior intention terbukti memiliki pengaruh positif dan tidak signifikan. Penelitian terdahulu yang membuktikan hipotesis ini adalah penelitian yang dilakukan oleh (Limantara, Jingga, \& Surja, 2018), (Gusman \& Ariyanti, 2019). Hal ini disimpulkan bahwa responden masyarakat Gunung Putri Bogor belum sepenuhnya percaya bahwa belanja online melalui Tokopedia mampu melindungi data pribadi dan bisa mengalami kerugian finansial saat berbelanja online di e-commerce Tokopedia. Selain itu pengguna Tokopedia belum percaya Tokopedia dapat menjaga kerahasiaan data pengguna dalam belanja online.

Berdasarkan pengujian pengaruh dari variabel behavioral intention terhadap use behavior terbukti memiliki pengaruh positif dan signifikan. Penelitian terdahulu yang membuktikan hipotesis ini adalah penelitian yang dilakukan oleh (Venkatesh et al., 2012), (Putra \& Ariyanti, 2014), (Trojanowski \& Kułak, 2017), (Gupta et al., 2018), dan (Ramdhani et al., 2017). Maka dapat disimpulkan bahwa terdapat minat dari responden untuk menggunakan layanan e-commerce Tokopedia dan kemungkinan akan digunakan dalam jangka waktu yang lama di kemudian hari karna manfaat yang dirasakan sangat menguntungkan bagi pengguna atau responden.

\section{Kesimpulan}

Performance expectancy, effort expectancy, social influence, facilitating condition, dan price value memiliki pengaruh positif dan signifikan terhadap behavioral intention. Artinya variabel tersebut merupakan faktor yang paling penting yang mempengaruhi behavioral intention pada e-commerce Tokopedia di Gunung Putri. Hedonic motivation, habit, dan trust memiliki pengaruh positif dan tidak signifikan terhadap behavioral intention. Artinya variabel tersebut merupakan bukan faktor yang paling penting yang mempengaruhi behavioral intention pada e-commerce Tokopedia di Gunung Putri. Facilitating condition, habit dan behavioral intention memiliki pengaruh positif dan signifikan terhadap use behavior. Artinya variabel tersebut merupakan faktor yang paling penting yang mempengaruhi use behavior pada e-commerce Tokopedia di Gunung Putri. 


\section{BIBLIOGRAFI}

Cahyani, Esty Dwi. (2019). Analisis Penerimaan Aplikasi Ruang Guru Sebagai Media Pemenuhan Informasi Akademik Siswa Sma Di Kota Surabaya Ditinjau Dari Model Utaut2. Universitas Airlangga. Google Scholar

Foon, Yeoh Sok, \& Fah, Benjamin Chan Yin. (2011). Internet banking adoption in Kuala Lumpur: an application of UTAUT model. International Journal of Business and Management, 6(4), 161. Google Scholar

Gupta, Anil, Dogra, Nikita, \& George, Babu. (2018). What determines tourist adoption of smartphone apps? Journal of Hospitality and Tourism Technology. Google Scholar

Gusman, Rio, \& Ariyanti, Maya. (2019). Identification Of The Factors Affecting The Adoption Of The Use Of Mygrapari Service Machines In Jakarta With The Unified Theory Of Acceptance And Use Of Technology 2 Model (Utaut 2)'. Asian Journal of Management Sciences \& Education, 8(2), 1-12. Google Scholar

Handayani, Rini. (2007). Psikologi Perkembangan Anak. Jakarta: Universitas Terbuka. Google Scholar

Harsono, Listyo D., \& Suryana, Lisady A. (2014). Factors affecting the use behavior of social media using UTAUT 2 model. Proceedings of the First Asia-Pacific Conference on Global Business, Economics, Finance and Social Sciences, 1-14. Google Scholar

Indrawati. (2014). The Use of Modified Unified Theory of Acceptance and Use of Technology to Predict the Behavioural Intention toward Website. Switzerland: Trans Tech Publications. Google Scholar

Indrawati, Indrawati, \& Utama, Kedar Priya. (2018). Analyzing 4G Adoption in Indonesia Using a Modified Unified Theory of Acceptance and Use of Technology 2. 2018 6th International Conference on Information and Communication Technology (ICoICT), 98-102. IEEE. Google Scholar

Kotler, Philip, \& Keller, Kevin Lane. (2016). Marketing management (15th global ed.). England: Pearson. Google Scholar

Limantara, Natalia, Jingga, Fredy, \& Surja, Stephanie. (2018). Factors Influencing Mobile Payment Adoption in Indonesia. 2018 International Conference on Information Management and Technology (ICIMTech), 373-377. IEEE. Google Scholar

Limayem, Moez, Hirt, Sabine Gabriele, \& Cheung, Christy M. K. (2007). How habit limits the predictive power of intention: The case of information systems continuance. MIS Quarterly, 705-737. Google Scholar 
Analisis Perilaku Konsumen dengan Model Modified Unified Theory of Acceptance and Use Technology 2 (UTUT2) pada E-Commerce Tokopedia

Putra, Gioliano, \& Ariyanti, Maya. (2014). Pengaruh Faktor-Faktor dalam Modified Unified Theory of Acceptance and Use of Technology 2 (UTAUT 2) terhadap Niat Prospective Users untuk Mengadopsi Home Digital Services PT. Telkom di Surabaya. Jurnal Manajemen Indonesia, 14(1), 59-76. Google Scholar

Putri, Dianty Anggraini. (2018). Analyzing Factors Influencing Continuance Intention of E-Payment Adoption Using Modified UTAUT 2 Model. 2018 6th International Conference on Information and Communication Technology (ICoICT), 167-173. IEEE. Google Scholar

Raman, Arumugam, \& Don, Yahya. (2013). Preservice teachers' acceptance of learning management software: An application of the UTAUT2 model. International Education Studies, 6(7), 157-164. Google Scholar

Ramdhani, Bachri, Rachmawati, Indira, \& Prabowo, Fajar. (2017). Pengaruh Adopsi Teknologi Layanan Uang Elektronik Telkomsel Cash Menggunakan Pendekatan Utaut 2. EProceedings of Management, 4(1). Google Scholar

Sekaran, Uma, \& Bougie, Roger. (2010). Research Methods For Business: A Skill Building Approach, Jhon Wiley dan Sons. Inc. Google Scholar

Tarhini, Ali, El-Masri, Mazen, Ali, Maged, \& Serrano, Alan. (2016). Extending the UTAUT model to understand the customers' acceptance and use of internet banking in Lebanon. Information Technology \& People. Google Scholar

Trojanowski, Mariusz, \& Kułak, Jacek. (2017). The impact of moderators and trust on consumer's intention to use a mobile phone for purchases. Central European Management Journal, 25(2), 91-116. Google Scholar

Venkatesh, Viswanath, Thong, James Y. L., \& Xu, Xin. (2012). Consumer acceptance and use of information technology: extending the unified theory of acceptance and use of technology. MIS Quarterly, 157-178. Google Scholar

Wibowo, Aditya, \& Ariyanti, Maya. (2016). Perilaku Penggunaan Smartphone Mewah Dengan Menggunakan Model Modified Unified Theory Of Acceptance And Use Of Technology 2 Bandung. EProceedings of Management, 3(2). Google Scholar

\section{Copyright holder:}

Bagus Maulana dan Adi Nurmahdi (2021)

First publication right:

Journal Syntax Literate

This article is licensed under:

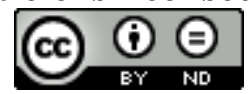

